Research Article

\title{
Comparative evaluation of antihypertensive drugs in the management of pregnancy-induced hypertension
}

\author{
Nita K. Patel ${ }^{\mathrm{a}, *}$, Mansi Gadhavi ${ }^{\mathrm{b}}$, Dhaval Gorasia ${ }^{\mathrm{c}}$, Manish R. Pandya ${ }^{\mathrm{d}}$
}

${ }^{\mathrm{a}}$ Assistant Professor, ${ }^{\mathrm{b}} 2^{\text {nd }}$ Year Resident, ${ }^{\mathrm{c}} 3^{\text {rd }}$ Year Resident, ${ }^{\mathrm{d}}$ Professor \& Head, Department of Obstetrics and Gynecology, C.U. Shah Medical College \& Hospital, Surendranagar 363001, India

Received: 7 October 2012

Revised: 19 October 2012

Accepted: 11 November 2012

*Correspondence to:

Dr. Nita K. Patel,

Email: pcpate127@gmail.com

\begin{abstract}
Background: Pregnancy-induced hypertension is associated with various adverse fetal and maternal outcomes. The use of anti-hypertensive drugs in pregnancy is controversial. We conducted a prospective study to evaluate the comparative effectiveness and safety of nifedipine, methyldopa and labetalol monotherapy in patients with pregnancy-induced hypertension.

Methods: A total of 60 pregnant women with blood pressure of 140/90 mm $\mathrm{Hg}$ or more with $\geq 1+$ proteinuria between 20 and 38 weeks of gestation were randomly allocated to receive nifedipine $(n=20)$, methyldopa $(n=20)$ or labetalol $(n=20)$. Blood pressure was measured at $0,6,24,48$ and $72 \mathrm{~h}$ of initiation of antihypertensive drugs. Patients were also followed up for development of adverse drug effects during this period.

Results: Antihypertensive treatment with methyldopa was associated with reduction in systolic blood pressure (SBP) by $50 \mathrm{mmHg}$ and diastolic blood pressure (DBP) by $30 \mathrm{mmHg}$ at $72 \mathrm{~h}$. For the same period treatment with nifedipine was associated with reduction in SBP by $54 \mathrm{mmHg}$ and DBP by 30 $\mathrm{mmHg}$. Treatment with labetalol was associated with reduction in SBP by 70 $\mathrm{mmHg}$ and DBP by $36 \mathrm{mmHg}$ at $72 \mathrm{~h}$.

Conclusions: Labetalol was more effective than methyldopa and nifedipine in controlling blood pressure in patients with pregnancy-induced hypertension while methyldopa and nifedipine are equally effective in controlling blood pressure.
\end{abstract}

Keywords: Antihypertensive, Pregnancy-induced hypertension (PIH), Preeclampsia, Nifedipine, Methyldopa, Labetalol

\section{INTRODUCTION}

Hypertension complicates almost $10 \%$ of pregnancies. ${ }^{1}$ Progression from mild to severe forms of hypertension during pregnancy is unpredictable and can be rapid. ${ }^{2}$ The use of anti-hypertensive drugs in pregnancy is controversial. The drug therapy has little place in the management of mild hypertension occurring late in the third trimester. Perinatal mortality has been shown to be lower in mild pregnancy-induced hypertension $(\mathrm{PIH}){ }^{3}$ When moderate or severe hypertension occurs with proteinuria, mortality rates are raised and active treatment results in a lower perinatal mortality rate. ${ }^{3}$ Management of PIH differs from that of hypertension in non-pregnant individuals in several important ways, with treatment generally being needed for a limited duration and at higher blood pressure (BP) targets in PIH. Further, treatment of PIH often involves adjustment between competing concerns for maternal health, gestational age of the infant and fetal exposure to antihypertensive drugs. The major goal of antihypertensive medication in PIH is to prevent or treat severe hypertension (generally defined as Blood Pressure (BP) of $\geq 160 / 110 \mathrm{mmHg}$ ) and its associated complications and to prolong pregnancy for as long as possible. ${ }^{4}$

In clinical trials, the benefits of antihypertensive treatment in PIH have been inconsistent. ${ }^{5-9}$ The choice of antihypertensive drugs in pregnancy is often limited due to fetal safety concerns. Three antihypertensive drugsnifedipine, methyldopa and labetalol have been demonstrated to be safe for use in the pregnant women and are commonly used for the management of various hypertensive disorders during pregnancy. ${ }^{10-15}$ Nifedipine is a calcium channel blocker. Methyldopa is a centrallyacting adrenergic antagonist that acts by stimulation of the central alpha 2 receptors, leading to a decrease in sympathetic nerve activity with resultant arterial dilatation 
and reduction in BP. Labetalol is a combined alpha- and beta-blocker and has the advantage over other beta blockers due to its additional arteriolar vasodilator action that helps to lower peripheral vascular resistance with little or no decrease in cardiac output.

The purpose of this study was to evaluate the comparative effectiveness and safety of nifedipine, methyldopa and labetalol monotherapy in patients with pregnancy-induced hypertension (PIH).

\section{METHODS}

This randomized and prospective study was conducted in 60 pregnant women with $\mathrm{PIH}$, who first presented between 20 and 38 weeks of gestation. The study was approved by the institutional ethics committee of the hospital. Informed consent was obtained from all the patients before enrollment. Medical and obstetric history taking and physical examination were performed at the time of initial recruitment. Conventional sphygmomanometer was used for BP measurement and phase V Koratokoff sounds were used to define diastolic BP. The measurements were taken in the sitting position in a chair after 20 minutes rest. Urinary protein excretion was measured with urine dipstick test. Selection of patients was restricted to those who, during pregnancy, had a BP of $140 / 90 \mathrm{~mm} \mathrm{Hg}$ or more with $\geq 1+$ proteinuria with urine dipstick test.

Patients with underlying chronic hypertension, history of antihypertensive medication in the current pregnancy, secondary hypertension, molar pregnancies, multiple pregnancy, placenta previa, congenital anomalies, renal disease, hematological disease, heart disease and diabetes were excluded. The patients were randomly allocated to receive nifedipine, methyldopa or labetalol. Nifedipine was started at a dose of 10-20 mg twice daily.
Methyldopa was started at a dose of 250-500 mg twice daily while labetalol was started at a dose of 100-400 mg twice daily. All the patients were followed for $72 \mathrm{~h}$. Blood pressure was measured at $0,6,24,48$ and $72 \mathrm{~h}$ of initiation of antihypertensive drugs. Patients were also followed up for development of adverse drug effects during this period. Blood pressure data are presented as mean for all three treatment groups.

\section{RESULTS}

A total of 60 eligible patients were randomized to receive nifedipine $(n=20)$, methyldopa $(n=20)$, or labetalol $(n=20)$. All three groups had comparable baseline and demographic characteristics. The changes in systolic blood pressure (SBP) and diastolic blood pressure (DBP) are shown in figure 1 and figure 2 respectively. Antihypertensive treatment with methyldopa was associated with reduction in systolic BP by $50 \mathrm{mmHg}$ and diastolic BP by $30 \mathrm{mmHg}$ at $72 \mathrm{~h}$. For the same period treatment with nifedipine was associated with reduction in systolic BP by $54 \mathrm{mmHg}$ and diastolic BP by $30 \mathrm{mmHg}$. Treatment with labetalol was associated with reduction in systolic BP by $70 \mathrm{mmHg}$ and diastolic BP by $36 \mathrm{mmHg}$ at $72 \mathrm{~h}$.

The common adverse effects reported are shown in figure 3. The commonest adverse effects noted were occipital headache (3-9\%), postural hypotension (3-8\%), tachycardia $(4-11 \%)$, and depression $(2-7 \%)$. Tachycardia (11\%) and occipital headache $(9 \%)$ were more common with nifedipine compared to methyldopa and labetalol groups. Postural hypotension and depression were more commonly reported side effects with methyldopa group $(8 \%)$ compared to nifedipine and labetalol group.

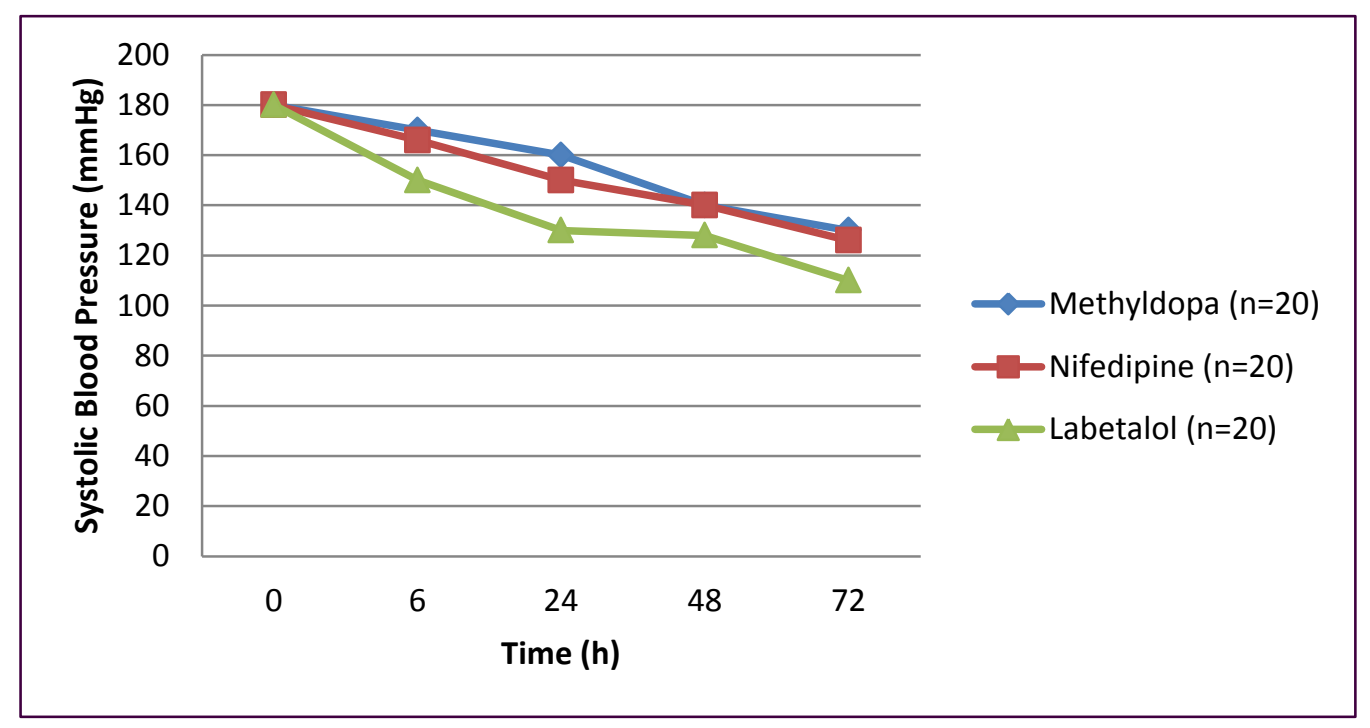

Figure 1: Effect of antihypertensive drugs on systolic blood pressure. 


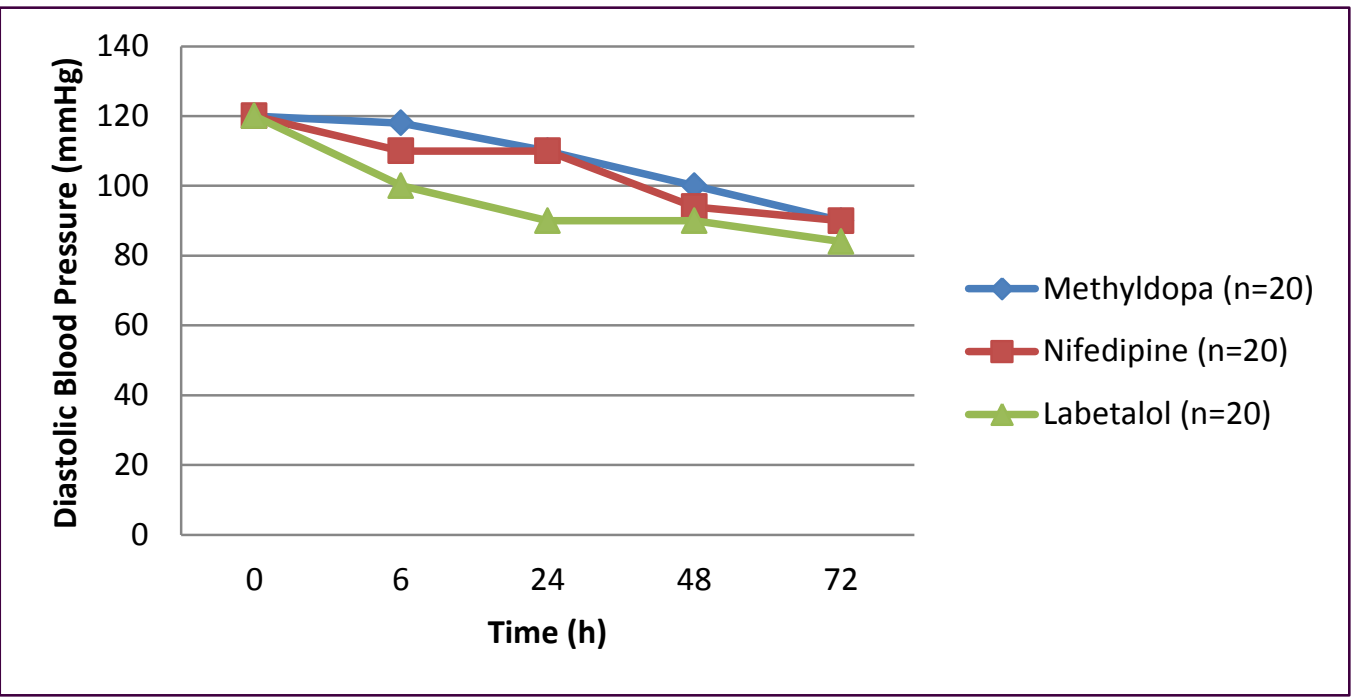

Figure 2: Effect of antihypertensive drugs on diastolic blood pressure.

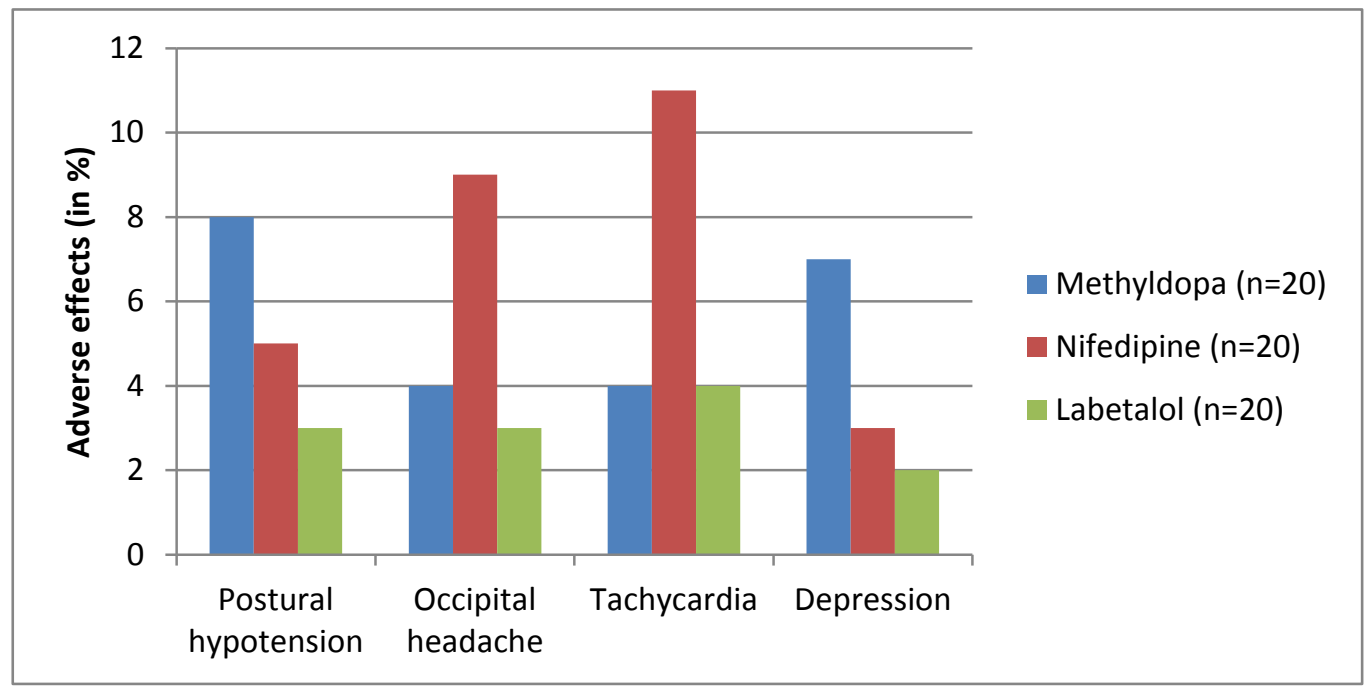

Figure 3: Comparison of adverse effects of antihypertensive drugs in patients with pregnancy-induced hypertension.

\section{DISCUSSION}

The results of the present study demonstrate that antihypertensive drugs were very effective in reduction of systolic and diastolic blood pressure. In the past an increasing variety of hypotensive drugs have been used in in treatment of PIH. Unlike this study where three different antihypertensive drugs were effective as monotherapy in controlling blood pressure other reports indicate the addition of another antihypertensive to control the blood pressure is frequently required. One of the studies found it necessary to add hydralazine to both treatment regimens of oxprenalol and methyldopa for improved blood pressure control. ${ }^{16}$ Combination drug therapy confuses an already complex condition involving the mother and the foetus. The reported effects of antihypertensive drugs on the placental circulation and therefore oxygenation of the foetus are conflicting. One of the studies has reported a two-thirds incidence of small, for gestation age, infants born to women on oral antihypertensive drugs. ${ }^{17}$

Unlike other antihypertensive drugs labetalol reduces peripheral resistance without significantly reducing maternal cardiac output and pulse rate. This may be an additional factor in maintaining adequate placental perfusion and therefore foetal oxygenation in the treatment of pregnancy hypertension with labetalol. 
Methyldopa is probably the most frequently used antihypertensive drug in pregnancy. Data suggest that the treatment of maternal hypertension with methyldopa may reduce the head circumference of infants where the drug has been prescribed between 16 and 20 weeks gestation. ${ }^{18}$ This may be the sensitive period for brain growth.

This study confirms the previous findings that labetalol is an effective and safe drug for use in the control of blood pressure in pregnancy-induced hypertension. The low incidence of maternal and foetal side-effects together with the excellent perinatal outcome in a condition usually accompanied by a high maternal and foetal mortality and morbidity confirms its suitability for use during pregnancy. ${ }^{19}$ The low incidence of pulmonary hyaline membrane disease suggests that it is the preferred drug in the treatment of pregnancy-induced hypertension. ${ }^{19}$

The results of the present study indicate that labetalol is more effective than methyldopa and nifedipine in controlling blood pressure in patients with pregnancyinduced hypertension while methyldopa and nifedipine are equally effective in controlling blood pressure.

\section{REFERENCES}

1. Lenfant C. National Education Program Working Group on High Blood Pressure in Pregnancy. Working group report on high blood pressure in pregnancy. J Clin Hypertens (Greenwich) 2001;3:75-88.

2. Sibai BM. Eclampsia. VI. Maternal-perinatal outcome in 254 consecutive cases. Am J Obstet Gynecol 1990;163:1049-54.

3. Leather HM, Humphreys DM, Baker P, Chadd MA. A controlled trial of hypotensive agents in hypertension in pregnancy. Lancet 1968;2:488-90.

4. ACOG Committee on Obstetric Practice. ACOG practice bulletin. Diagnosis and management of preeclampsia and eclampsia. Number 33, January 2002. American College of Obstetricians and Gynecologists. Int J Gynaecol Obstet 2002;77:6775.

5. Magee LA, Ornstein MP, Von Dadelszen P. Management of hypertension in pregnancy. Br Med J 1999;318:1332-6.

6. Plouin PF, Breart G, Llado J. A randomized comparison of early with conservative use of antihypertensive drugs in the management of pregnancy-induced hypertension. $\mathrm{Br} \quad \mathrm{J}$ Obstet Gynecol 1990;97:134-41.

7. Elhassan EM, Mirghani OA, Habour AB. Methyldopa versus no drug treatment in the management of mild preeclampsia. East Afr Med J 2002;79(4):172-5.

8. Magee LA, Elran E, Bull SB. Risks and benefits of beta receptor blockers for pregnancy hypertension: Overview of the randomized trials. Eur J Obstet Gynecol Reprod Biol 2000;88:15-26.

9. Pickles CJ, Broughton PF, Symonds EM. A randomized placebo controlled trial of labetalol in the treatment of mild to moderate pregnancy induced hypertension. Br J Obstet Gynaecol 1992;99:964-8.

10. Giannubilo SR, Bezzeccheri V, Cecchi S, Landi B, Battistoni GI, Vitali P, Cecchi L, Tranquilli AL. Nifedipine versus labetalol in the treatment of hypertensive disorders of pregnancy. Arch Gynecol Obstet 2012;286:637-42.

11. El-Qarmalawi AM, Morsy AH, Al-Fadly A. Labetalol vs methyldopa in the treatment of pregnancy-induced hypertension. Int $\mathbf{J}$ Gynecol Obstet 1995;49:125-30.

12. Khedun SM, Moodley J, Naicker T. Drug management of hypertensive disorders of pregnancy. Pharmacol Ther 1997;74:221-58.

13. Mabie WC. Management of acute severe hypertension and encephalopathy. Clin Obstet Gynecol 1999;42:519-31.

14. Linton DM, Anthony J. Critical care management of severe pre-eclampsia. Intensive Care Med 1997;23:248-55.

15. Lamming GD, Broughton Pipkin F, Symonds EM. Comparison of the alpha and beta blocking drug, labetalol, and methyl dopa in the treatment of moderate and severe pregnancy-induced hypertension. Clin Exp Hypertens 1980;2:865-95.

16. Gallery ED, Saunders DM, Hunyor SN, Gyory AZ. Randomised comparison of methyldopa and oxprenolol for treatment of hypertension in pregnancy. Br Med J 1979;1(6178):1591-4.

17. Welt SI, Dorminy JH 3rd, Jelovsek FR, Crenshaw MC, Gall SA. The effects of prophylactic management and therapeutics on hypertensive disease in pregnancy: preliminary studies. Obstet Gynecol 1981;57:557-65.

18. Ounsted MK, Moar VA, Good FJ, Redman CW. Hypertension during pregnancy with and without specific treatment; the development of the children at the age of four years. $\mathrm{Br} \mathrm{J}$ Obstet Gynaecol 1980;87:19-24.

19. Michael CA.The evaluation of labetalol in the treatment of hypertension complicating pregnancy. Br J Clin Pharmacol 1982;13(1 Suppl):127S-131S.

doi: 10.5455/2319-2003.ijbcp003412

Cite this article as: Patel NK, Gadhavi M, Gorasia D, Pandya MR. Comparative evaluation of antihypertensive drugs in the management of pregnancy-induced hypertension. Int J Basic Clin Pharmacol 2012;1:174-7. 